\title{
A STELLA Model for Evaluating the Efficiency of an Integrated Multi-Trophic Aquaculture System (IMTA)
}

\author{
Cicilia Kambey and Ik Kyo Chung \\ Department of Oceanography, Pusan National University \\ Busan Metro City, 46241, Republic of Korea \\ Correspondence to : cicilia_kambey@yahoo.com
}

\begin{abstract}
Cicilia Kambey and Ik Kyo Chung. 2015. A STELLA Model for Evaluating the Efficiency of an Integrated Multi-Trophic Aquaculture System (IMTA). Aquacultura Indonesiana, 16 (2): 38-49. Interest is increasing in Integrated Multi-Trophic Aquaculture Systems (IMTA) that encourage the development of environmentally friendly practices. By combining fed aquaculture with nearby extractive aquaculture, an IMTA can minimize the negative ecological impacts of conventional monoculture farms while expanding their economic base. To evaluate the efficiency of such a system, we applied dynamic STELLA modeling based on nitrogen content. The application of seaweed co-culturing reduced the level of dissolved inorganic nitrogen (DIN) by 20 to $35 \%$ over the short term whereas DIN values declined annually by 68 to $88 \%$. When sea cucumber was incorporated into the scheme, the amount of particulate organic nitrogen was decreased by up to $50 \%$. Ultimately, we plan to introduce potential strategic guidelines for IMTA implementation that might improve management and predictive capabilities while enhancing the social acceptability of such a system.
\end{abstract}

Keywords: IMTA; Modeling; Nitrogen; Seaweed

\section{Introduction}

Coastal waters are susceptible to a variety of land and coastal-based pollutants. Their direct discharge from various sectors continues to increase. Extensive aquaculture operations now constitute a major source of nutrient inputs to coastal waters and have become a general concern in environmental systems because an excess of some nutrients can lead to chronic bioaccumulations and eutrophication. One suggested approach to developing a balanced ecosystem is Integrated Multi-Trophic Aquaculture (IMTA), a scheme designed to reuse waste products and reduce the potential for eutrophication (Troell et al., 2009; Chopin, 2011; Ren et al., 2012).

Although recently re-introduced, IMTAs are not a new concept but rather they represent the old wisdom of ancient farming that minimizes the effects of nutrient effluents, particularly those from aquaculture activities in coastal waters (Chopin, 2013). Integrated fed aquaculture that involves organic and inorganic extractive organisms is urgently required. One feature of an IMTA is that the waste products from fed-aquaculture species, such as shrimp or finfish, are recaptured and converted into fertilizer, feed, and energy for extractive culture species, such as plants and other farm animals that can eat organic waste. Therefore, an IMTA system not only can be employed to produce valuable crops but can also mitigate the harm of pollutants and help bio-remediate coastal waters. Various aspects of an IMTA system have been studied worldwide, involving different systems and a variety of organisms (Chung et al., 2002; Carmona et al., 2006; Wang et al., 2012; Wu et al., 2015).

Because of the rapid and often uncontrolled expansion of aquaculture, additional efforts are necessary to combat challenges in ecosystem management of these systems. Any IMTA design must consider site characteristics and select organisms that contribute the necessary synergies if one is to understand the entire environmental system (Lamprianidou et al., 2015). When knowledge is inadequate for properly preparing an IMTA design, many problems can arise, including inappropriate combinations of organisms (Nizzoli et al., 2005; Navarrete-Mier et al., 2010), or a reduction in water movement that leads to an increase in populations of pathogen bacteria and high mortality rates for the cultured organisms (De Silva, 2012). Therefore, stocking density is an important component of any design (Wu, 1995; $\mathrm{Wu}$ et al., 2015). As demand increases for sustainable solutions to environmental and economic problems, new methods must be developed that can predict the outcomes of policy decisions (Costanza and Voinov, 2001).

To generate a sustainable and effective system of aquaculture practice, we used the 
dynamic STELLA model for simulating the complexities of each IMTA component. In the study described here, we evaluated the efficiency of a model to reduce nitrogen in such systems and promote high productivity by associated components. We focused on a land-based integrated closed system and validated this model using data reported by Shpigel et al. (1993), Neori et al. (2000), and Schuenhoff et al. (2003).

\section{Methods}

\section{Model Description}

We developed our concept model of IMTA using STELLA software (isee systemUSA) and integration with Euler's methods. The selected running periods for simulation were based on data obtained via field cultivation over $28 \mathrm{~d}, 58 \mathrm{~d}$, or $12 \mathrm{mo}$, with DT (delta time) set at 0.25 . This model combined fed aquaculture with other extractive aquaculture using data reported by Shpigel et al. (1993), Neori et al. (2000), and Schuenhoff et al. (2003).
The four main components of culture included fed organisms (finfish), suspended filtering feeders (bivalves), inorganic extractive organisms (seaweed), and benthic detrivores (sea cucumber), as recommended by Chopin (2011) (Figure 1). In addition, our land-based system considered co-culturing with abalone because of its high value. In contrast, different combinations of organisms have been used in earlier studies, including finfish/bivalve/seaweed (Shpigel et al., 1993), abalone/finfish/seaweed (Neori et al., 2000), and short-term cultivation finfish/seaweed (Schuenhoff et al., 2003). Each connection in this IMTA model assessed how those components might influence the availability of nitrogen. Furthermore, the IMTA model presented the Nremoval process for each extractive organism in terms of its uptake, metabolism, and harvest.

We conducted a literature review (see References in Table 1) to identify the most reasonable and representative parameters to use as our coefficients in developing the model equations (Table 2).

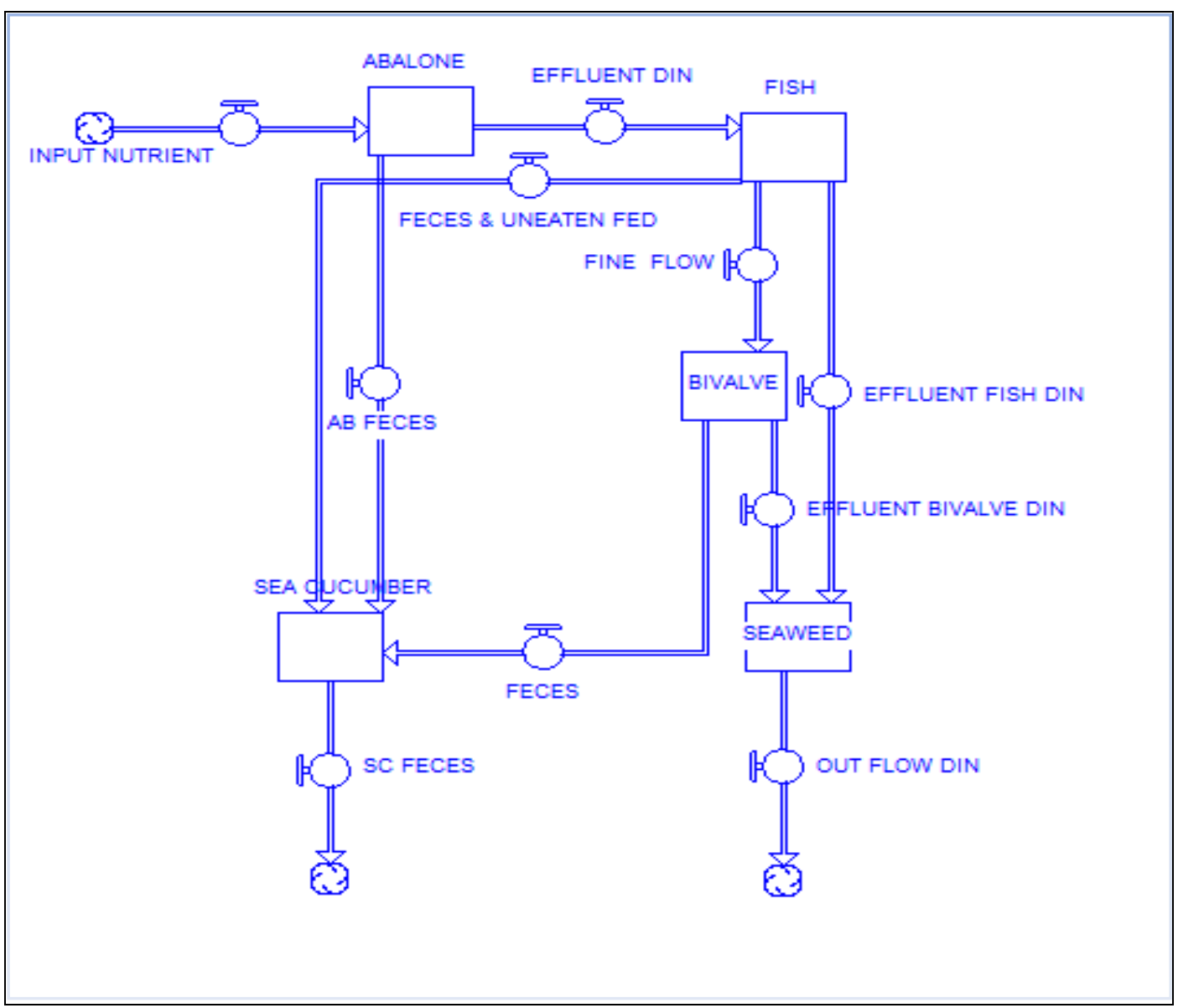

Figure 1. Conceptual model for land-based IMTA bioremediation of excess nitrogen. 
Table 1. Variables and coefficients used as components in STELLA model.

\begin{tabular}{|c|c|c|c|c|}
\hline Variable & Description & Value & Unit & Reference \\
\hline SGR fish & Maximum growth rate of fish & $0.45-1$ & $\% / d$ & Cotton et al., 2003; Le Ruyet et al., 2004 \\
\hline SGR $A b$ & Maximum growth rate of abalone & 1.33 & $\% / d$ & Neori et al., 2000 \\
\hline SGR $B v$ & Maximum growth rate of bivalve & 0.6 & $\% / d$ & Shpigel et al., 1993 \\
\hline SGR Sw & Maximum growth rate of seaweed & 1.67 & $\% / d$ & This study \\
\hline SGR Sc & Maximum growth rate of sea cucumber & 0.85 & dimensionless & Ren et al., 2012 \\
\hline e DIN fish & Ratio excretion DIN of fish & $45-49$ & Percentage & Lamprianidou et al., 2015; Islam, 2005 \\
\hline e DIN ab & Ratio excretion DIN of abalone & 37 & Percentage & Neori et al., 2000 \\
\hline e DIN bv & Ratio excretion DIN of bivalve & 25 & Percentage & Shpigel et al., 1993 \\
\hline e DIN sw & Ratio excretion DIN of seaweed & 25 & Percentage & This study \\
\hline$\delta r$ fish & Mortality of fish & 0.05 & $/ \mathrm{yr}$ & Neori et al., 2000 \\
\hline$\delta r a b$ & Mortality of abalone & 0.15 & /yr & Neori et al., 2000 \\
\hline$\delta r b v$ & Mortality of bivalve & 0.17 & /yr & Shpigel et al., 1993 \\
\hline$\delta r \mathrm{sw}$ & Ratio of seaweed discarded & 0.0047 & $/ d$ & Neori et al., 2000 \\
\hline$d$ fish & Feces of fish & 10 & Percentage & Islam, 2005 \\
\hline$d a b$ & Feces of abalone & 26 & Percentage & Neori et al., 2000 \\
\hline$d b v$ & Feces of bivalve & 26 & Percentage & Neori et al., 2000 \\
\hline$d s c$ & Feces of sea cucumber & 20 & Percentage & Nelson et al., 2012 \\
\hline Un ffish & Uneaten pellet of fish & 20 & Percentage & Islam, 2005 \\
\hline FPON & Fine particle suspended & 3 & Percentage & Buschmann et al., 2009 \\
\hline$W f$ & Water flow & 0.8 & dimensionless & (estimated) \\
\hline SW exp. & Seaweed exported & $19-20$ & Percentage & (estimated) \\
\hline Remov.Eff & Removal efficiency of seaweed & 75 & Percentage & This study \\
\hline absorption SC & Sea cucumber absorption & 70 & Percentage & Nelson et al., 2012 \\
\hline FE bivalve & Filtration efficiency & 0.8 & dimensionless & Shpigel et al., 1993 \\
\hline
\end{tabular}

Table 2. Equations used to calculate values of component variables in IMTA system.

\begin{tabular}{|c|c|}
\hline Description & Equation \\
\hline 1. Abalone & $d$ Abalone $=A b(t-d t)+(A b$ nutrient- $A b$ harvest- $A b D I N-A b$ mortality- $A b$ feces $) x d t$ \\
\hline 2. Bivalve & $d$ Bivalve $=B v(t-d t)+(B v$ nutrient- $B v$ harvest- $B v D I N-A B$ mortality- $B v$ feces $) x d t$ \\
\hline 3. Fish & $d$ Fish $=$ Fish $(t-d t)+($ feed flow - Fs mortality - Fs harvest $-F$ feces-DIN released $) x d t$ \\
\hline 4. Seaweed & $d$ Seaweed $=$ Seaweed $(t-d t)+($ DIN Input-Nutrient DIN output $-S w$ discarded $-S w$ harvest - Swexported $) x d t$ \\
\hline 5. Sea cucumber & $d$ Sea cucumber $=$ Sea cucumber $(t-d t)+($ Absorption-Sc harvest $-S c$ feces $) x d t$ \\
\hline 6. Abalone nutrient $\mathrm{N}$ & seaweed $x$ SW exp. \\
\hline 7. Abalone harvest & Abalone $x$ SGR $a b$ \\
\hline 8. Ab DIN & Abalone $\times$ eDIN $a b$ \\
\hline 9. Ab mortality & Abalone x $\delta r a b$ \\
\hline 10. Ab feces mucus & Abalone $x \mathrm{~d} a b$ \\
\hline 11. Feed flow & (Initial Feed + Ab DIN) $x$ Fish/Init (Fish) \\
\hline 12. Fs mortality & Fish $x \delta$ fish \\
\hline 13. Fs harvest & Fish $\times$ SGR fish \\
\hline 14. Fs feces & Fish $x d$ fish \\
\hline 15. Fish DIN released & Fish x e DIN fish \\
\hline 16. DIN input to seaweed* & (Fish DIN released $+*$ Bivalve DIN) $x$ water flow \\
\hline 17. Seaweed harvest & Seaweed $x$ SGR Sw x Converter \\
\hline 18. Seaweed discarded & Seaweed $x \delta r s w$ \\
\hline 19. Seaweed exported $* *$ & Seaweed $x$ SW exp. \\
\hline 20. Sea cucumber uptake & Total PON $x$ absorption SC \\
\hline 21. Sea cucumber harvest & Sea cucumber $x$ SGR $S c$ \\
\hline 22. Sea cucumber feces & Se cucumber $x d s c$ \\
\hline 23. Total organic $(\mathrm{PON})$ & uneaten feed + Ab fecesmисиs + Bivalve fecesmucus $+F s$ feces \\
\hline 24. Bivalve nutrient $\mathrm{N}$ & Fine PON x FE Bivalve \\
\hline 25. Bivalve harvest & Bivalve $x S G R B v$ \\
\hline 26. Bivalve DIN & Bivalve $\mathrm{x} e D I N b v$ \\
\hline 27. Bivalve mortality & Bivalve $\mathrm{x} \delta r b v$ \\
\hline 28. Bivalve feces mucus & Bivalve $x d b v$ \\
\hline 29. Sensitivity Analysis & $\{\mathrm{V}(1.1 p)-\mathrm{V}(0.9 p)\} / \mathrm{V}(p) 0.2$ \\
\hline
\end{tabular}

\section{Cultured Organisms}

For the fish component, we modeled feed as the main input of $\mathrm{N}$ into the system while fish excretion was the main output of dissolved inorganic nitrogen (DIN). Feces from the fish were modeled as the main output of particulate organic nitrogen $(\mathrm{PON})$. The harvesting period for finfish
(Neori et al., 2000; Shpigel et al., 1993; Schuenhoff et al., 2003) was simulated at the end of the culturing period. As fertilizer for inorganic food production, the DIN from fish is useful for seaweed culture. The selection of bivalve organisms that are cultured in a land-based IMTA system can vary according to culturing purposes. 
For example, Schuenhoff et al. (2003) did not include bivalves in their short-term system. Neori et al. (2000) did not use filter feeders but substituted co-culture with abalone, which was fed approximately $20 \%$ of the harvested seaweed. Shpigel et al. (1993) used oysters and clams as filter feeders in the IMTA system. Fine particles that formed from uneaten feed and fish feces were also modeled as variables that influenced bivalve growth.

As an autotroph, seaweed has an important role in IMTA because it is the final extractive organism that can take up DIN and reduce the amount of nitrogen in a system. For example, Ulva served as the bioremediation species in models by Shpigel et al. (1993) and Schuenhoff et al. (2003) while Neori et al. (2000) used both Ulva and Gracilaria.

The IMTA model was completed by incorporating sea cucumber as an extractor of large-particle organic components. As such, these organisms remove PON from fish and bivalve waste. For our model, we estimated the initial number of sea cucumbers to predict the absorption of PON. That is, an increase in sea cucumber biomass was calculated as being equivalent to the amount of PON removed from the system. We also modeled the feces of sea cucumber as an additional variable for $\mathrm{N}$ inputs.

\section{Simulation Model}

While emphasizing nitrogen removal in our land-based IMTA model, we assumed that the physical parameters reflected ideal culturing conditions, e.g., appropriate levels for light intensity, temperature, $\mathrm{pH}$, salinity, and oxygen. Uptake of DIN by the seaweed component was limited by the rate of water flow. This dimensionless variable was modeled here as ranging from 0.1 (fastest flow) to 0.8 (moderate) to 1.0 (steady). Overall, we discounted the processes of nitrification and denitrification, assuming here that all of the $\mathrm{N}$ from fish waste was distributed homogenously in the system and was available for uptake. This allowed us to focus only on the bioremediation capacity of each organism, i.e., their ability to take up $\mathrm{N}$ and increase the amount of harvested biomass.

The abalone/finfish/seaweed/sea cucumber system of Neori et al. (2000) produced a fed-release value over their 12-mo culture period of $3.918 \mathrm{~g} \mathrm{~N}$ and a Feed Conversion Ratio (FCR) value of 2.0, whereas the 12-mo finfish/bivalve/seaweed/sea cucumber system of Shpigel et al. (1993) had a fed-release value of $1226 \mathrm{~kg} \mathrm{~N}$ and an FCR value of 3.0. Whereas Neori et al. (2000) considered the amount of dissolved nitrogen taken up by Ulva and Gracilaria, Shpigel et al. (1993) and Schuenhoff et al. (2003) used only Ulva to predict bioremediation waste. Seaweed was modeled as being harvested multiple times over the period in order to maintain stocking densities. Its yield was then exported to abalone culture, while bivalve oysters and clams fed on fine PON. Fine PON was modeled as $3 \%$ of the total (Buschmann et al., 2009). The maximum amount of $\mathrm{N}$ harvested was assumed to be equivalent to the $\mathrm{N}$ content measured in seaweed biomass. Schuenhoff et al. (2003) data were simulated for 28- and 51-d culture periods.

\section{Sensitivity Analysis}

We conducted sensitivity analyses by varying each component by $10 \%$ in either direction over 12 mo. Data from Neori et al. (2000) were used and all calculations were based on a formulation by Everett et al. (2007). The equation of sensitivity analysis are show also in Table 2 . Where $\mathrm{V}(1.1 p)$ is the value of variable $p$ increased by $10 \%, \mathrm{~V}(0.9 p)$ is the value of variable $p$ decreased by $10 \%$, and $\mathrm{V}(p)$ is the value in an unchanged state. If any calculated value was close to 1 , we considered sensitivity to be proportional to the original parameter while values close to 2 were considered proportional to $p^{2}$.

\section{Results}

\section{Performance of IMTA Components}

Simulation results reported by Neori et al. (2000) indicated that their abalone component produced DIN $104 \mathrm{~g} \mathrm{~N} / \mathrm{yr}$ while field data revealed $150 \mathrm{~g} \mathrm{~N} / \mathrm{yr}$. Seaweed was continuously harvested to maintain a desirable stocking density in the pond system. Approximately $20 \%$ of the yield was exported to the abalone component, accounting for $325 \mathrm{~g} \mathrm{~N} / \mathrm{yr}$ (i.e., $37 \mathrm{~kg}$ fresh weight, or FW; 8.1 to $9.5 \mathrm{~g} \mathrm{~N} \mathrm{~kg} / \mathrm{FW}$ ). The amount of abalone harvested was estimated by the model as $113 \mathrm{~g} / \mathrm{yr}$ versus 154 $\mathrm{g} / \mathrm{yr}$ based on field data. Figure 2 shows the fluctuations in annual seaweed production when cocultured with an abalone component. 


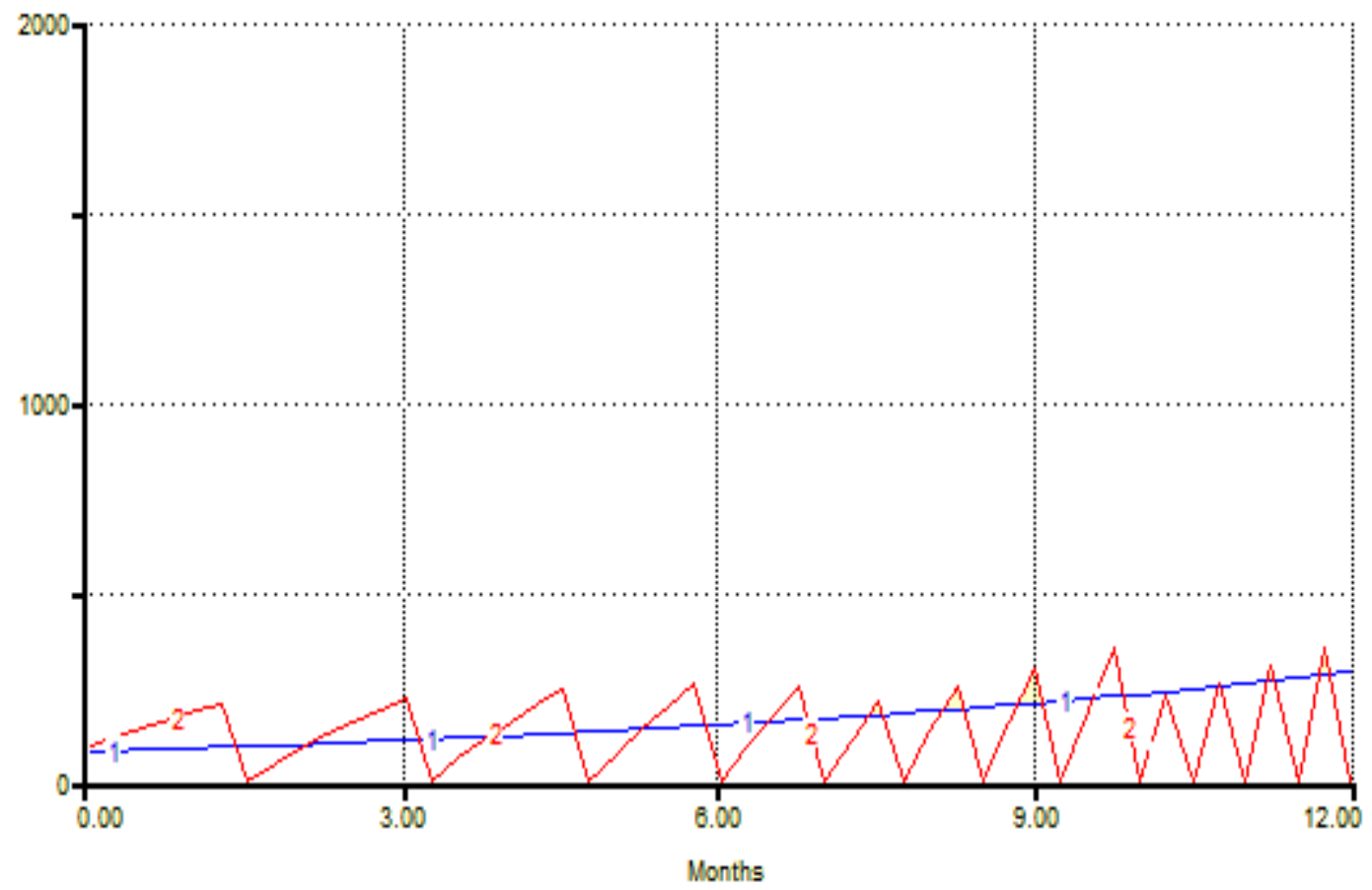

Figure 2. Simulation of seaweed biomass (grams of N) exported to abalone culture (Neori et al., 2000).

The DIN waste produced by abalone flowed into the fish component and the amount of feed for that component was set in the model according to field calculations. For example, if the growth rate per day was $0.67 \%$ (Neori et al., 2000 ; or $0.70 \%$ from the model estimate), then a fish initially weighing $12 \mathrm{~kg}$ would produce 30 $\mathrm{kg} / \mathrm{m}^{2}$ biomass (modelled). By contrast, that yield would be only $28 \mathrm{~kg} / \mathrm{m}^{2}$ if the field data were used for predicting the final harvest. Our simulation also showed that the DIN and feces in fish effluent contained 1,944 $\mathrm{g} \mathrm{N}$ and $413 \mathrm{~g} \mathrm{~N}$, respectively, per annum, compared with $1,879 \mathrm{~g}$ $\mathrm{N}$ and $392 \mathrm{~g} \mathrm{~N}$, based on field data. Although seaweed culture could directly take up DIN from fish culture, water flow still limited that capacity. For both Ulva and Gracilaria, $195 \mathrm{~kg}$ were harvested (model) versus $134 \mathrm{~kg}$ (field). The model simulation also indicated that seaweed could remove up to $88 \%$ of the total DIN from fish effluent through harvest. Therefore, the total amount of organic waste from fish and abalone feces, plus uneaten pellets, increased in our IMTA model. When sea cucumber was incorporated, the level of total organic compounds was reduced by $48 \%$, and the model calculated an absorption capacity of $70 \%$.

Modeling based on data from Shpigel $e t$ al. (1993) presented a simulated scenario that utilized oysters and clams as filter feeders. The variable 'fed input' directly influenced $\mathrm{N}$ contents throughout the entire system, with input values of $1,226 \mathrm{~kg} \mathrm{~N} / \mathrm{yr}$ and an estimated harvest of $201 \mathrm{~kg} \mathrm{~N}$ via fish ( $16 \%$ as yield $\mathrm{N})$. By contrast, the field data indicated $185 \mathrm{~kg} \mathrm{~N} / \mathrm{yr}$ from the harvest, even though potential production was estimated to be $318 \mathrm{~kg} \mathrm{~N} / \mathrm{yr}$ ( $26 \%$ as yield nitrogen). Fish effluent produced $558 \mathrm{~kg}$ $\mathrm{N}$ as DIN and $118 \mathrm{~kg} \mathrm{~N} / \mathrm{yr}$ as particulate organic compounds, while the amount from uneaten feed pellets was $245 \mathrm{~kg} \mathrm{~N} / \mathrm{yr}$. By filtering fine organic particulates, the bivalves processed $32 \mathrm{~kg} \mathrm{~N} / \mathrm{yr}$ and produced $44 \mathrm{~kg} \mathrm{~N} / \mathrm{yr}$ as DIN, which then continued from fish and bivalves through to the seaweed component. Seaweed took up 68\% of the DIN by converting it into $410 \mathrm{~kg} \mathrm{~N}$ as harvested biomass. This compared with a harvest of $273 \mathrm{~kg} \mathrm{~N}$ estimated from the field data. Figure 3 shows that, during 2 mo of culturing, the amount of $\mathrm{N}$ taken up by seaweed could surpass the level of DIN in a system. The addition of a sea cucumber component improved the capacity for total PON absorption by $44 \%$, such that the extra biomass could take up $174 \mathrm{~kg} \mathrm{~N} / \mathrm{yr}$. The complexities of an IMTA system based on the research of Shpigel et al. (1993), is depicted in Figure 4. 


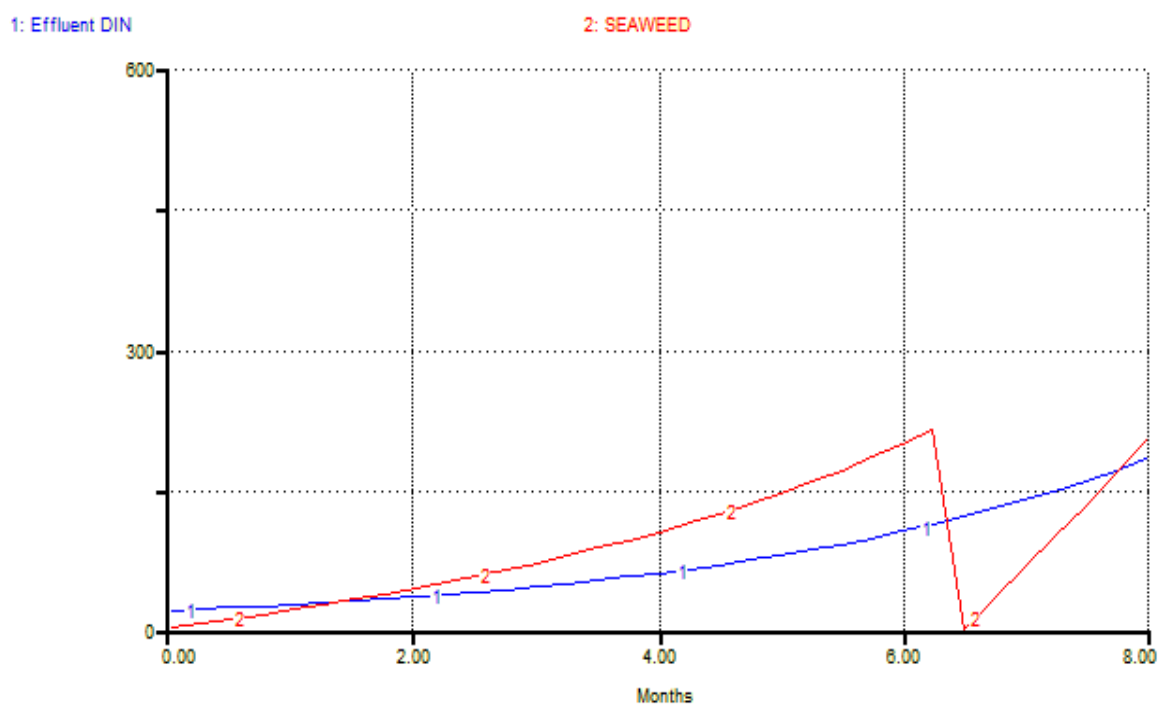

Figure 3. Simulation model showing that concentrations of dissolved nitrogen $(\mathrm{kg} \mathrm{N})$ are surpassed by levels taken up by seaweed (Shpigel et al., 1993)

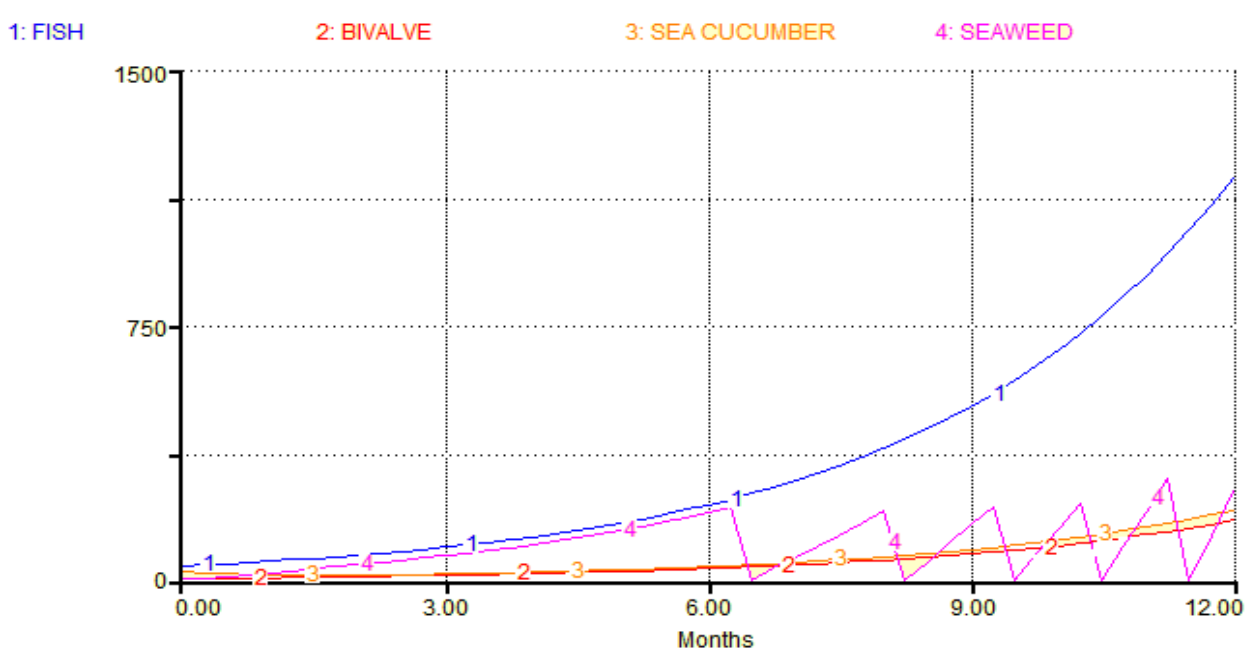

Figure 4. Simulation of annual nitrogen flux $(\mathrm{kg} \mathrm{N})$ when integrating fish, bivalve, seaweed and sea cucumber, based on data from Shpigel et al. (1993).

On the semi-commercial scale, as first described by Schuenhoff et al. (2003), our model evaluated data obtained through intensive sampling over $51 \mathrm{~d}$ and $28 \mathrm{~d}$ of culture. For both periods, the estimated annual fish harvest was $53.0 \mathrm{~kg}$ and $28.2 \mathrm{~kg}$, respectively, values that were quite similar to field measurements of 52.0 $\mathrm{kg}$ and $27.0 \mathrm{~kg}$, respectively. However, differences were found in effluent DIN, with model values of $3,535 \mathrm{~g} \mathrm{~N}$ and $1,881 \mathrm{~g} \mathrm{~N}$ for 51 and $28 \mathrm{~d}$, respectively, versus $4,760 \mathrm{~g} \mathrm{~N}$ and $3,670 \mathrm{~g} \mathrm{~N}$, respectively, from the field. Likewise, predictions for PON from fish feces were $752 \mathrm{~g}$ $\mathrm{N}(51 \mathrm{~d})$ and $400 \mathrm{~g} \mathrm{~N}(28 \mathrm{~d})$ from the model compared with $1,261 \mathrm{~g} \mathrm{~N}(51 \mathrm{~d})$ and $881 \mathrm{~g} \mathrm{~N}(28$ d) from the field. For seaweed, the gains were
$138.3 \mathrm{~kg}(1,245 \mathrm{~g} \mathrm{~N})$ at $51 \mathrm{~d}$ and $41.4 \mathrm{~kg}(373 \mathrm{~g}$ $\mathrm{N})$ at $28 \mathrm{~d}$ for the model and $171.3 \mathrm{~kg}(1,542 \mathrm{~g}$ $\left.\mathrm{N} / \mathrm{m}^{2}\right)$ at $51 \mathrm{~d}$ and $75.3 \mathrm{~kg}\left(678 \mathrm{~g} \mathrm{~N} / \mathrm{m}^{2}\right)$ at $28 \mathrm{~d}$ for the field. The simulation model of nitrogen contents in biomass from fish and seaweed during $28 \mathrm{~d}$ of culture is presented in Figure 5.

Finally, the loss of DIN from the entire system, due to flow and unassimilated forms of $\mathrm{N}$, was modeled at $1,488 \mathrm{~g} \mathrm{~N}(51 \mathrm{~d})$ and $753 \mathrm{~g} \mathrm{~N}$ $(28 \mathrm{~d})$ versus field measurements of $3,154 \mathrm{~g} \mathrm{~N}$ (51 d) and 2,853 g N (28 d). Table 3 shows how our model values compared with results from previous pilot studies that utilized all components incorporated into an IMTA system based on nitrogen contents. 


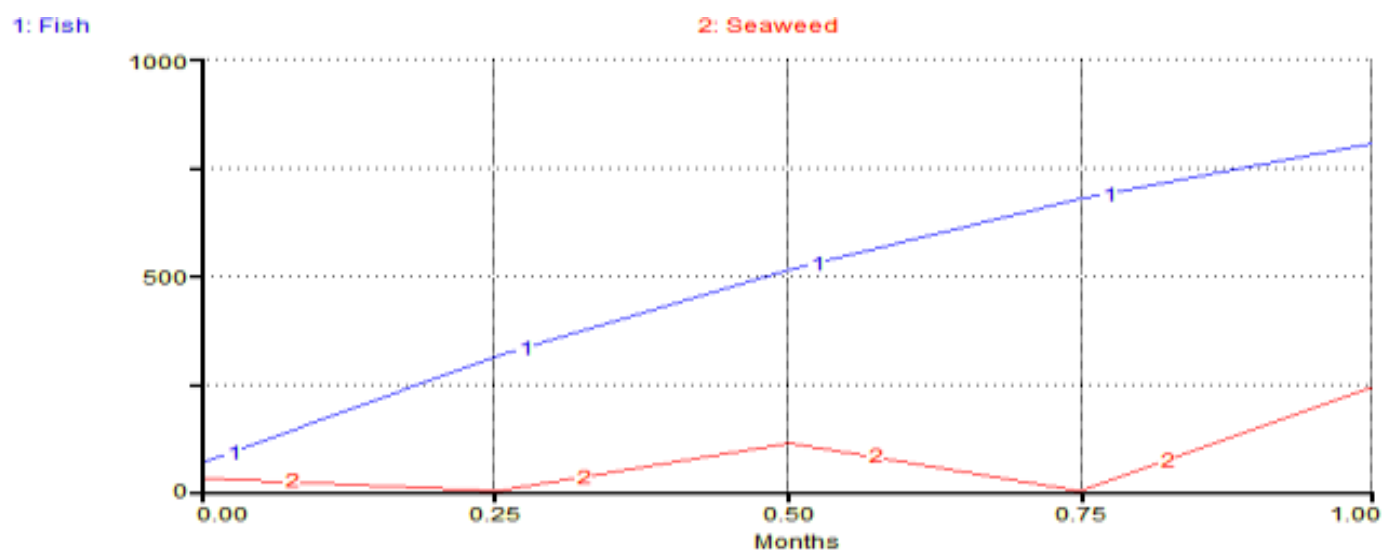

Figure 5. Simulated levels of nitrogen flux (grams of N) when fish are co-cultured with seaweed for $28 \mathrm{~d}$, based on data from Schuenhoff et al. (2003).

Table 3. Comparisons of estimated values between our model and those previously published, incorporating the nitrogen budget.

\begin{tabular}{|c|c|c|c|c|c|c|c|c|}
\hline Variable component & $\begin{array}{c}\text { Neori et } \\
\text { al. }(2000) \text { in } \\
\text { grams } N\end{array}$ & $\begin{array}{c}\text { Model } \\
\text { in grams } \\
N\end{array}$ & $\begin{array}{c}\text { Shpigel et } \\
\text { al. (1993) } \\
\text { in kg N } \\
\end{array}$ & $\begin{array}{l}\text { Model } \\
\text { in } k g N\end{array}$ & $\begin{array}{c}\text { Schuenhoff } \\
\text { et al. (2003) } \\
\text { in } \mathrm{g} N(\mathrm{~A})^{*}\end{array}$ & $\begin{array}{l}\text { Model in } \\
g(\mathrm{~A})^{*}\end{array}$ & $\begin{array}{l}\text { Schuenhoff } \\
\text { et al. (2003) } \\
\text { in } \mathrm{g} N(\mathrm{~B})^{* *}\end{array}$ & $\begin{array}{c}\text { Model } \\
\text { in } g N(\mathrm{~B})^{* *}\end{array}$ \\
\hline \multicolumn{9}{|l|}{ ABALONE } \\
\hline 1. Seaweed input & 410 & 325 & $\mathrm{~N} / \mathrm{A}$ & N/A & N/A & N/A & N/A & N/A \\
\hline 2. Abalone harvest & 154 & 113 & N/A & N/A & N/A & N/A & N/A & N/A \\
\hline 3. Abalone DIN output & 150 & 104 & N/A & $\mathrm{N} / \mathrm{A}$ & N/A & N/A & N/A & N/A \\
\hline 4. Abalone feces & 107 & 73 & N/A & $\mathrm{N} / \mathrm{A}$ & $\mathrm{N} / \mathrm{A}$ & N/A & $\mathrm{N} / \mathrm{A}$ & $\mathrm{N} / \mathrm{A}$ \\
\hline (Deficit/Surplus) & (1) & 35 & & & & & & \\
\hline \multicolumn{9}{|l|}{ FISH } \\
\hline 1. Fed input & 3918 & 3918 & 1226 & 1226 & 7416 & 7416 & 5184 & 5184 \\
\hline 2. Harvest & 768 & 829 & 185 & 201 & 1809.75 & 1512 & 1097 & 804 \\
\hline 3. DIN output & 1879 & 1944 & 122 & 558 & 4760 & 3535 & 3670 & 1881 \\
\hline 4. Uneaten feed & $N / A$ & 805 & 662 & 245 & $N / A$ & 1483 & $N / A$ & 1037 \\
\hline 5. Feces & 392 & 413 & 122 & 118 & 1261 & 752 & 881 & 400 \\
\hline Abalone DIN input & 150 & 104 & N/A & N/A & $\mathrm{N} / \mathrm{A}$ & $\mathrm{N} / \mathrm{A}$ & N/A & N/A \\
\hline (Deficit/Surplus) & 1069 & 31 & 135 & 104 & (414) & 134 & (464) & 1062 \\
\hline \multicolumn{9}{|l|}{ BIVALVE (OYSTER AND } \\
\hline \multicolumn{9}{|l|}{ CLAM) } \\
\hline 1. Bivalve feed input & N/A & N/A & 784 & 196 & $\mathrm{~N} / \mathrm{A}$ & N/A & N/A & N/A \\
\hline 2. Bivalve harvest & N/A & N/A & 177 & 32 & N/A & N/A & N/A & N/A \\
\hline 3. Bivalve DIN output & $\mathrm{N} / \mathrm{A}$ & N/A & 306 & 44 & N/A & N/A & N/A & N/A \\
\hline 4. Bivalve feces & N/A & N/A & 78 & 28 & N/A & N/A & N/A & N/A \\
\hline (Deficit/Surplus) & & & 223 & 92 & & & & \\
\hline \multicolumn{9}{|l|}{ SEAWEED } \\
\hline 1. DIN input & 1879 & 1944 & 306 & 602 & 2305 & 3535 & 950 & 1881 \\
\hline 2. Seaweed harvest & 762 & 1,387 & 275 & 410 & 1542 & 1245 & 678 & 373 \\
\hline 3. Seaweed discarded & 67 & 0 & 0 & 0 & 0 & 0 & 0 & 0 \\
\hline 4. DIN output & 394 & 391 & 30.7 & 120 & 0 & 707 & 0 & 376 \\
\hline $\begin{array}{l}\text { 5. Seaweed export to } \\
\text { abalone }\end{array}$ & 339 & 325 & 0 & 0 & 0 & 0 & 0 & 0 \\
\hline 6. Seaweed import & 53 & 0 & 0 & 0 & 0 & 0 & 0 & 0 \\
\hline (Deficit/Surplus) & 264 & (159) & 0.3 & 72 & 763 & 1583 & 272 & 1132 \\
\hline \multicolumn{9}{|l|}{ SEA CUCUMBER } \\
\hline 1.Total organic compound & $N / A$ & 1,291 & $N / A$ & 392 & $N / A$ & N/A & $N / A$ & N/A \\
\hline $\begin{array}{l}\text { 2. Sea cucumber organic } \\
\text { absorption }\end{array}$ & $N / A$ & 908 & $N / A$ & 274 & $N / A$ & N/A & $N / A$ & N/A \\
\hline 3. Sea cucumber harvest & $N / A$ & 624 & $N / A$ & 174 & $N / A$ & N/A & $N / A$ & N/A \\
\hline 4. Sea cucumber feces & $N / A$ & 147 & $N / A$ & 41 & $N / A$ & N/A & $N / A$ & N/A \\
\hline (Deficit/Surplus) & & 520 & & 177 & & & & \\
\hline System dimension & $3.3 \mathrm{~m}^{3}$ & $3.3 \mathrm{~m}^{3}$ & $\begin{array}{l}750 \mathrm{~m}^{3} \\
(\mathrm{C})^{* * *}\end{array}$ & $750 \mathrm{~m}^{3}$ & $\begin{array}{c}40 \mathrm{~m}^{3} \\
\text { (D) } * * * *\end{array}$ & $40 \mathrm{~m}^{3}$ & $40 \mathrm{~m}^{3}$ & $40 \mathrm{~m}^{3}$ \\
\hline
\end{tabular}

*51 d culture $\quad * * * 750 \mathrm{~m}^{3}$ fish pond with $184 \mathrm{~m}^{3}$ bivalve pond, $315 \mathrm{~m}^{3}$ seaweed pond

$* * 28 \mathrm{~d}$ culture $\quad * * * * 40 \mathrm{~m}^{3}$ fish pond with seaweed yield shown in $\mathrm{m}^{2}$ 


\section{Nitrogen Budget}

In estimating nitrogen fluxes within an IMTA system, our model calculated both deficit and surplus $\mathrm{N}$, presenting a nitrogen budget for each component. As the most abundant $\mathrm{N}$ distributor, fish accounted for annual surpluses of $31 \mathrm{~g} \mathrm{~N}$ to $104 \mathrm{~kg} \mathrm{~N}$. For the abalone component, 35 $\mathrm{g} \mathrm{N} / \mathrm{yr}$ was modeled as the excess while the bivalve component showed a surplus of $92 \mathrm{~kg} \mathrm{~N} / \mathrm{yr}$. In contrast, a deficit of $159 \mathrm{~g} \mathrm{~N} / \mathrm{yr}$ was predicted for the seaweed component, while sea cucumbers were associated with surpluses of $520 \mathrm{~g} \mathrm{~N}$ to $177 \mathrm{~kg}$ N/yr. Under short-term culture, the largest surplus was found with the simulated seaweed component, i.e., $1,132 \mathrm{~g} \mathrm{~N}$ at $28 \mathrm{~d}$ and $1,583 \mathrm{~g} \mathrm{~N}$ at $51 \mathrm{~d}$. Details of nitrogen budgeting associated with each component are shown in Table 3.

\section{Production Capacity}

This simulation model was used to determine the market value of each component, based on productivity. We also evaluated the capacity to reduce nitrogen levels as an ecosystem service provided by extractive components. For example, the nutrient trading credit (NTC) was defined as having an average value of $0.35 \%$ nitrogen for seaweed, which meant that the NTC for this component ranged from 10.00 to $30.00 \mathrm{USD} / \mathrm{kg}$. The values of organic extractive components, such as seaweed were estimated based on Chopin (2011) and shellfish were estimated, based work by Rose et al. (2014) at value 150.00 USD per pound of $\mathrm{N}$ removal.

Abalones are the most commercially valuable gastropods, with worldwide market prices of USD 43.00 to $100.00 / \mathrm{kg} \quad \mathrm{FW}$ (www.bbc.business.com). Our model-simulated production over 12 mo was $113 \mathrm{~g} \mathrm{~N}$ and approximately $7 \mathrm{~kg} \mathrm{FW}$, with a value of USD
301.00 to 700.00. Fish culture resulted in production capacity of up to $30 \mathrm{~kg}$. Based on a commercial value of approximately $7.40 \mathrm{USD} / \mathrm{kg}$ for Sparus aurata (www.Fish.com), this meant that $3.3 \mathrm{~m}^{3}$ of pond culture for fish could yield USD $222.00 / \mathrm{yr}$.

As an extractive organism, seaweed is more beneficial because of both its economic and ecosystem values, based on market price and NTCs, respectively. Our model found that the total seaweed harvest per annum was approximately $190 \mathrm{~kg}$, accounting for $1,712 \mathrm{~g} \mathrm{~N}$. Therefore, economic values were USD 13,871.90 (USD $73.01 \times 190 \mathrm{~kg}$; biofuel price) for Ulva (Nikolaisen et al., 2011) or USD 95.00 (USD $0.50 \times 190 \mathrm{~kg}$; common market price) if we used Gracilaria (WWF Indonesia, 2014). Furthermore, the NTC for these seaweeds ranged from USD 17.00 to USD $51.00(1,712 \mathrm{~g} \mathrm{~N} \mathrm{x}$ USD 10.00-30.00; Chopin, 2011).

Another extractive organic remover, the sea cucumber, can be quantified by NTC, although its worth has not yet been determined. Its value would be approximately USD 1.50 to $58.00 / \mathrm{kg}$ according to prices on current international trade markets.

\section{Sensitivity Analysis}

Our model simulation showed that the most sensitive components were seaweed and sea cucumber (Table 4). A change of $10 \%$ in their variable rates of growth influenced their productivity by 2.1 -fold (seaweed) and 2.2-fold (sea cucumber). By comparison, those fold-changes were 1.0 to 1.16 for abalone and 0.78 to 1.77 for the fish component. This new model was relatively insensitive to most variables. In fact, only three parameters had sensitive values $>1.5$ : uneaten feed, seaweed harvest, and sea cucumber harvest.

Table 4. Sensitivity analysis of component variables in IMTA system.

\begin{tabular}{lccccc}
\hline \multicolumn{1}{c}{ Variable* } & Normal value & Effect +10\% & Effect -10\% & Unit & Sensitivity analysis \\
\hline Abalone & & & & & \\
Abalone harvest & 113 & 125 & 101 & $\mathrm{~g} \mathrm{~N} / \mathrm{yr}$ & 1.06 \\
Abalone DIN released & 104 & 115 & 92 & $\mathrm{~g} \mathrm{~N} / \mathrm{yr}$ & 1.15 \\
Abalone PON released & 73 & 81 & 64 & $\mathrm{~g} \mathrm{~N} / \mathrm{yr}$ & 1.16 \\
Fish & & & & & \\
Fish harvest & 829 & 800 & 670 & $\mathrm{~g} \mathrm{~N} / \mathrm{yr}$ & 0.78 \\
Fish DIN released & 1944 & 1884 & 1567 & $\mathrm{~g} \mathrm{~N} / \mathrm{yr}$ & 0.82 \\
Fish feces released & 413 & 400 & 333 & $\mathrm{~g} \mathrm{~N} / \mathrm{yr}$ & 0.81 \\
Uneaten feed & 805 & 973 & 687 & $\mathrm{~g} \mathrm{~N} / \mathrm{yr}$ & 1.78 \\
Seaweed \& Sea cucumber & & & & $\mathrm{g} \mathrm{N} / \mathrm{yr}$ & 2.10 \\
Seaweed harvest & 1712 & 1920 & 1200 & $\mathrm{~g} \mathrm{~N} / \mathrm{yr}$ & 2.20 \\
Sea cucumber harvest & 624 & 698 & 423 & & \\
\hline *Based on data from Neori et al., 2000 & & &
\end{tabular}




\section{Discussion}

This new model can potentially estimate the flux in nitrogen removal by each incorporated organism depending upon its capacity to take up and assimilate that nutrient into its biomass, without regard for the influence of anthropogenic activities. Our goal with this model was to demonstrate that implementing an IMTA can reduce the occurrence of negative environmental impacts and add economic and ecosystem benefits at harvest time. Although such simulation models often optimize production capacity. Because it is focused on crop productivity and nutrient removal, $\mathrm{N}$ contents vary according to the time period used for development and assessment prior to harvest.

The utility of this model for estimating DIN levels in effluent and fish feces at the time of harvest is similar to that associated with predictions based on field data. However, our model results differ from those described from the model of Schuenhoff et al. (2003) in terms of effluent and particulate organics (i.e., feces), here revealing a rate of $47 \%$ for effluent DIN versus $64 \%$ reported by Schuenhoff et al. (2003). The rate of DIN excretion found here is similar to that shown in studies by Islam (2005) and Bouwman et al. (2013), in which values ranged from $30 \%$ to $54 \%$ for general finfish. Castine et al. (2013) calculated a similar rate, $48 \%$, for trout fish. In contrast, Neori and Krom (1991) determined a rate of $66 \%$ for the finfish $S$. aurata while Folke and Kautsky (1989) reported 62\% DIN removed by Salmo salar. Another contrast in assimilation rates was found for particulate organic feces, i.e., $17 \%$ predicted by the model of Schuenhoff $e t$ al. (2003) versus $10 \%$ from our model and those of Gowen and Bradbury (1987), as well as Wang et al. (2012) and Bouwman et al. (2013) for salmon and general finfish, respectively. These differences in excretion rates are not only species specific but also vary according to feeding strategies, e.g., frequency, size of fish, and their ontogeny (Bolliet et al., 2001; Islam, 2005). Moreover, stocking density and physical force are other factors that affect rates of metabolism (Wu, 1995).

The incorporation of a filtration pond in the model by Schuenhoff et al. (2003), but not in our model, also influenced those values. Such ponds can reduce the level of DIN by 50 to $70 \%$ before it passes to a seaweed biofilter. Therefore, applying certain harvesting quotas to manage seaweed stocking densities can help decrease the amount of nitrogen within a culture system. Figure 2 illustrates the correlation between seaweed $\mathrm{N}$ biomass and DIN flow, increasing during stages of active growth but decreasing at harvest time. As a main input of $\mathrm{N}$, the amount of feed can be altered to increase the stability of sinking rates and optimize fish sizes (Wu, 1995). Likewise, the quality of a nutritional diet $\mathrm{N}$ on feed can be changed from feeding with trash fish to supplying artificial feeds (Xu et al., 2007). In general, advances in feed nutrition technology have had an important role in determining nutrient contents within the environment of an aquaculture system.

This model showed that seaweed could take up 20 to $88 \%$ of the available DIN. During short periods of culture, those rates can range from 20 to 35\% (Schuenhoff et al., 2003) while longer terms mean that 68 to $88 \%$ of the excess DIN can be taken up within the system. These contrasts might be explained by variations in light levels and photoperiods that are related to seasonal changes as well as to the capacity of nutrient reserves (Harrison and Hurd, 2001; Broch and Slagstad, 2012). Uptake rates might also be affected by shorter culture periods or decisions to harvest fish at a developmental stage where DIN excretion is maximized. Therefore, adjustments must be made when co-culturing seaweed and fish.

To exploit the high rates of nutrient uptake by seaweed, planners should select genera such as Ulva, which can remove nearly $80 \%$ of the excess $\mathrm{N}$ and under some conditions, up to $100 \%$ of the ammonium (Cohen and Neori, 1991; Troell et al., 1999; Macchiavello and Bulboa, 2014). Gracilaria is another suitable candidate because of its high economic value (Yang et al., 2015 ) as well as its ability to remove at least $80 \%$ of the ammonium (Chopin et al., 2001) and up to 95\% during the springtime (Buschmann et al., 1996). Because of their different morphological features, Ulva is often used for water treatments, e.g., recirculating-flow systems, while Gracilaria is valuable for mass production. Nonetheless, our model was able to predict values similar to those estimated by Neori et al. (2000) for potential seaweed harvests.

The last component of this simulated IMTA system incorporated sea cucumber as a deposit feeder to PON. One benefit of our model was that uneaten feed could be considered part of PON while that system also modeled feces, a variable that could affect the availability of total PON. Decreasing the amounts of PON depends 
upon the rates of feeding and ingestion by deposit species (Slater and Carton, 2007). As a slowgrowing organism that also ingests food slowly, sea cucumber can survive for several months without additional food, and individuals require more than one year reaching market size. Nevertheless, Cucumaria frondosa has been suggested as a suitable extractive organism for an IMTA system (Nelson et al., 2012) because it can potentially remove 44 to $48 \%$ of total PON when harvested. Therefore, co-culturing sea cucumber can play as significant a role as seaweed in an integrated system.

We used model simulations to determine the nutrient budget in an IMTA system because failing to estimate nutrient levels when developing a management plan can have unintended negative consequences for coastal or marine environments. Our model enabled us to predict nutrient imbalances for each component by examining stocking densities or by focusing on physical factors, such as water flow or speed of currents, but retention times and size dimensions of a culture site also affected nutrient in the system (Sara et al., 2012; Chopin et al., 2012; Rose et al., 2014).

Modeling can be applied to detect nutrient surpluses or deficits in a system. Our model discounted any negative impacts such as through eutrophication. Surplus organic nutrients can be controlled by incorporating suspended organisms or sea cucumbers in the bottom layers. Therefore, when devising an IMTA system, one must analyze nutrient outputs and fluxes in order to mitigate possible imbalances.

Productivity can be modeled for all system components. However, the challenge when estimating capacity is to assess cultivation costs as easily as possible. Recognizing economic benefits and providing economic incentives can make the expansion of management plans more profitable. For example, Ulva, when used as a biofuel, has a higher market value than Gracilaria. Therefore, wisely selecting the most appropriate organism(s) for co-cultivation can also lead to greater environmental improvements (Navarete-Mier et al., 2010; Chopin et al., 2012).

Strong emphasis has been placed on the co-culture of abalone with seaweed, while integration culture of seaweed in an aquaculture system has been suggested for worldwide applications (Chung et al., 2002, 2011; Neori et al., 2007; Ridler et al., 2007; Chopin, 2001, 2012). Additional feeding strategies can be a suitable option if model simulations detect a decline in production. By introducing additional food such as commercial feed, biomass yields can be increased although profitability can be diminished as a consequence. However, when one examines the overall capital budget, using only waste from one organism component can increase farm revenues (Ridler et al., 2007) and minimize environmental damages (Chopin, 2011).

Finally, reducing nutrient concentrations through the use of biofilter organisms, such as seaweed, bivalves, and sea cucumber, is a critical part of a bioremediation system. Therefore, we believe our land-based aquaculture model can be productive because it includes such a biofilter system. Furthermore, our sensitivity analyses demonstrated that the STELLA model is adequate for predicting reasonable outcomes when comparing between model and field data.

\section{Conclusion}

This model estimated the $\mathrm{N}$-removal capacity for each component in a land-based system of aquaculture that considered the role of nutrient waste control. Our results serve as an appropriate strategic guideline for IMTA implementation that can increase management and predictive capacities and improve the social acceptability of such systems.

\section{Acknowledgements}

This work has been supported by a grant from the National Research Foundation of Korea (NRF-2013R1A1A2009359) to IKC and from the Ministry of Education (BK21 plus Grant 21A20131500003). The authors are grateful to Prof. T.S. Lee for his kind guidance in model development.

\section{References}

Bouwman, L., A. Beusen, P.M. Glibert, C. Overbeek, M. Pawlowski, J. Herera, S. Muslow, R. Yu, and M. Zhou. 2013. Mariculture: significant and expanding cause of coastal nutrient enrichment. Environmental Research Letters, 8:1-5

Bolliet, V., M. Azzaydi, and T. Boujard. 2001. Effect of feeding time on feed intake and growth. In D. Houlihan, T. Boujard and M. Jobling (Eds) Food Intake in Fish. Blackwell Publishing Company, Oxford UK. pp 233249 
Broch, J.B. and D. Slagstad. 2012. Modelling seasonal growth and composition of the kelp Saccharina latisima. Journal of Applied Phycology, 24:759-776

Buschmann, A.H., M. Troell, N. Kautsky, and L. Kautsky. 1996. Integrated tank cultivation of salmonids and Gracilaria chilensis (Gracilariales Rhodophyta). Hydrobiologia, 326/327:75-82

Buschmann, A.H., F. Cabello, K. Young, J. Carvajal, D.A. Varela, and L. Henriquez. 2009. Salmon aquaculture and ecosystem health in Chile: analysis and regulation, environmental impact and bioremediation systems. Ocean and Coastal Management, 52:243-249

Carmona, R., G.P. Kraemer, and C. Yarish. 2006. Exploring Northeast American and Asian species of Porphyra for use in an integrated finfish-algal aquaculture system. Aquaculture, 252:54-65

Castine, S.A., A.D. McKinnon, N.A. Paul, L.A. Trott, and R. de Nys. 2013. Review. Waste water treatment for land-based aquaculture: improvement and value-adding alternatives in model system from Australia. Aquaculture Environment and Interaction, 4:285-300

Chopin, T. 2011. Progression of the integrated multi trophic aquaculture (IMTA) concept and upscaling of IMTA system towards commercialization. Aquaculture Europe, 36 (4):5-12

Chopin, T. 2013. Aquaculture, integrated multi trophic (IMTA). In R.A. Meyers (Ed) Encyclopedia of Science and Technology, 12:542-564

Chopin, T., A.H. Buschmann, C. Halling, M. Troell, N. Kautsky, A. Neori, G.P. Kraemer, J.A.Z. Gonzales, C. Yarish, and C. Neefus. 2001. Integrating seaweed into marine aquaculture system: a key toward sustainability. Journal of Phycology, 37:975986

Chopin, T., J. Cooper, G. Reid, S. Cross, and C. Moore. 2012. Open water integrated multi tropic aquaculture: environment biomitigation and economic diversification of fed aquaculture by extractive aquaculture Review of Aquaculture, 4:209-220

Chung, I.K., Y.H. Kang, C. Yarish, G.P. Kraemer, and J.A. Lee. 2002. Application of seaweed cultivation to the bioremediation of nutrientrich effluent. Algae, 17(3):1-10

Chung, I.K., J. Beardall, S. Mehta, D. Sahoo, and S. Stojkovic. 2011. Using marine macroalgae for carbon sequestration. A critical appraisal Journal of Applied Phycology, 23:877-886

Cohen, I. and A. Neori. 1991. Ulva lactuca biofilter for marine fish pond effluent I ammonium uptake kinetics and nitrogen content. Botanica Marina, 34:141-149
Costanza, R. and A. Voinov. 2001. Modeling ecological and economic systems with STELLA: Part III. Ecological Modeling, 143:1-7

Cotton, C.F., R.I. Walker, and T.C. Recicar. 2003. Effect of temperature \& salinity on growth of juvenile black sea bass with implication for aquaculture. North American Journal of Aquaculture, 65:330-338

De Silva, S.S. 2012. Aquaculture: a newly emergent food production sector- and perspectives of its impacts on biodiversity and conservation. Biodiversity Conservation, 21:3187-3220

Everett, J.D., M.E. Baird, and I.M. Suthers. 2007. Nutrient and plankton dynamics in an intermittently closed/open lagoon, Smiths Lake, south-eastern Australia: an ecological model. Estuarine, Coastal and Shelf Science, 72:690-702

Folke, C. and N. Kautsky. 1989. The role of ecosystems for a sustainable aquaculture. Ambio 18:234-243

Gowen, R.J. and N.B. Bradbury.1987. The ecological impact of salmonid farming in the coastal waters; a review. Oceanography and Marine Biology, 25:563-575

Harrison, P.J. and C.I. Hurd. 2001. Nutrient physiology of seaweed: application of concept to aquaculture. Cahiers de Biologie Marine, 42:71-82

Islam, M.S. 2005. Nitrogen and phosphorus budget in coastal and marine cage aquaculture and impact of nutrient loading on ecosystem: review and analysis towards model development. Marine Pollution Bulletin, 50:48-61.

Lamprianidou, F., T. Telfer, and L.G. Ross. 2015. A model for optimization of the productivity and bioremediation efficiency of marine integrated multitrophic aquaculture. Estuarine, Coastal and Shelf Science, 164:253-264

Le Ruyet, J.P., K. Mahe, N. Le Bayon, and H. Le Delliou. 2004. Effect of temperature on growth \& metabolism in a Mediterranean population of European sea bass Dicantrarchus labrax. Aquaculture, 237:269280

Macchiavello, J. and C. Bulboa. 2014. Nutrient uptake efficiency of Gracilaria chilensis and Ulva lactuca in an IMTA system with red abalone Haliostis rufescens. Latin American Journal of Aquatic Research, 42(3):523-533

Navarrete-Mier, F., C. Sanz-Lazaro, and A. Martin. 2010. Does bivalve molusc polyculture reduce marine finfish farming environmental impact? Aquaculture, 306:101-107 
Nelson, E.J., B.A. Macdonald, and S.M.C. Robinson. 2012. The absorption efficiency of suspension feeding sea cucumber Cucumaria frondosa and its potential as an extractive integrated multi trophic aquaculture (IMTA) species. Aquaculture, 370-371:19-25

Neori, A. and M.D. Krom. 1991. Nitrogen and phosphorus budget in an intensive marine fishpond; the importance of microplankton. In C.B. Cowey and C.Y. Cho. (Eds). Proceedings of First International Symposium on Nutritional Strategy in Management of Aquaculture Waste. University of Guelph, Ontario. pp 187-205

Neori, A., M. Shpigel, and D. Ben-Ezra. 2000. A sustainable integrated system for culture fish, seaweed and abalone. Aquaculture, 186:279291

Neori, A., M. Troell, T. Chopin, C. Yarish, A. Critchley, and A.H. Buschmann. 2007. The need for a balanced ecosystem approach to blue revolution aquaculture. Environment; Science \& Policy for Sustainable Development, 49:36-43

Nikolaisen, L., P.D. Jensen, K.S. Bech, J. Dahl, J. Busk, T. Brodsgaard, M.B. Rasmussen, A. Bruhn, A.B. Bjerre, H.B. Nielsen, K.R. Albert, P. Ambus, Z. Kader, S. Heiske, B. Sander, and E.R. Schmidt. 2011. Energy production for marine Biomass (Ulva Lactuca). PSO Project No. 2008-1-0050. pp 1-72

Nizzoli, D., D.T. Welsh, M. Bartoli, and P. Viaroli. 2005. Impact of mussel (Mytilus galloprovincialis) farming on oxygen consumption and nutrient recycling in a eutrophic coastal lagoon. Hydrobiologia, 550:183-198

Ren, J.S., J.S. Dozey, D.R. Plew, J. Fang, and M. Gall. 2012. An ecosystem model for optimizing production in integrated multi trophic aquaculture systems. Ecological Modeling, 246:34-46

Ridler, N., M. Wowchuk, B. Robinson, K. Barrington, T. Chopin, S. Robinson, F. Page, G. Reid, M. Szemerda, J. Sewuster, and S.B. Travis. 2007. Integrated multi trophic aquaculture (IMTA) a potential strategic choice for farmers. Aquaculture Economics and Management, 11:99-110

Rose, J. M., S.B. Bricker, M.A. Tedesco, and G.F. Wikfors. 2014. A role for shellfish aquaculture in coastal nitrogen management. Environment Science and Technology, 48:2519-2525

Sara, G., G.K. Reid, A. Rinaldi, V. Palmer, M. Troell, and S.A.L.M. Kooijman. 2012. Growth and reproduction simulation of candidate shellfish species at fish cage in southern mediterranean; dynamic energy budget (DEB) modeling for integrated multi trophic aquaculture. Aquaculture, 324-325:259-266

Schuenhoff, A., M. Shpigel, I. Lupatasch, A. Ashkenazi, F.E. Msuya, and A. Neori. 2003. A semi recirculating, integrated system for culture of fish and seaweed. Aquaculture, 221:167-181

Shpigel, M., A. Neori, M.D. Popper, and H. Gordin. 1993. A proposed model for "environmentally clean" land -based culture of fish, bivalve and seaweed. Aquaculture, 117:115-128

Slater, M.J. and A.G. Carton. 2007. Survivorship and growth of the sea cucumber Australostichopus (Stichopus) mollis (Hutton 1872) in polyculture trials with green lipped mussel farm. Aquaculture, 272:389-398

Troell, M., N. Kautsky, and C. Folke. 1999. Applicability of integrated coastal aquaculture system. Ocean and Coastal Management, 42:63-69

Troell, M., A. Joyce, T. Chopin, A. Neori, A.H. Buschmann, and J.G. Fang. 2009. Ecological engineering in aquaculture potential for integrated multi trophic aquaculture (IMTA) in marine offshore system. Aquaculture, 297(1-4):1-9

Wang, X., L.M. Olsen, K.I. Reitan, and Y. Olsen. 2012. Discharge of nutrient waste from salmon farms: environmental effect and potential for integrating multi trophic aquaculture. Aquaculture Environment and Interaction, 2:267-283

Wu, H., Y. Huo, F. Han, Y. Liu, and P. He. 2015. Bioremediation using Gracilaria chouae coculture with Sparus macrochephalus to manage the nitrogen and phosphorus balance in an IMTA system in Xiangshan Bay, China. Marine Pollution Bulletin, 91:272-279

Wu, R.S.S. 1995. The environmental impact of marine fish culture: towards a sustainable future. Marine Pollution Bulletin, 31:159-166

WWF Indonesia. 2014. Better management practice: budidaya rumput laut Gracilaria sp. di tambak. Panduan Perikanan Skala Kecil, hlm.1-32

Xu, Z., X. Lin, Q. Lin, Y. Yang, and Y. Wang. 2007. Nitrogen, phosphorus and energy waste output of four marine cage culture fish fed with trash fish. Aquaculture, 263:130-141

Yang, Y., Z. Chai, Q. Wang, W. Chen, Z. He, and S. Jiang. 2015. Cultivation of seaweed gracilaria in Chinese coastal waters and its contribution to environmental improvements. Algal Research, 9:236-244 